\title{
Active Students Are Healthier and Happier Than Their Inactive Peers: The Results of a Large Representative Cross-Sectional Study of University Students in Ireland
}

\author{
Marie H. Murphy, Angela Carlin, Catherine Woods, Alan Nevill, Ciaran MacDonncha, \\ Kyle Ferguson, and Niamh Murphy
}

\begin{abstract}
Background: Time spent in university represents a period of transition and may be an appropriate time to promote physical activity among young adults. The aim of this study was to assess participation of university students in sport and physical activity in Ireland and to explore the association between physical activity and perceptions of overall health, mental health, and happiness. Methods: The Student Activity and Sport Study Ireland was a cross-sectional online survey among a representative sample $(\mathrm{n}=8122)$ of university students in Ireland. Binary logistic regressions were performed to examine associations between selfreported physical activity and gender (predictor variables) and individual perceptions of overall health, mental health, and happiness (binary outcomes). Results: Only 64.3\% of respondents met the recommended level of 150 minutes of moderate to vigorous physical activity per week with males significantly more active than females (72.1\% vs $57.8 \%$ meeting guidelines). Those meeting physical activity guidelines were more likely to report greater overall health and higher mental health and happiness scores compared with their inactive peers. Conclusions: Active students enjoy better health (overall and mental) and are happier than their inactive peers. This provides a clear rationale for providing students with opportunities to be active at university. The data provide a baseline to monitor changes in physical activity patterns.
\end{abstract}

Keywords: physical activity, sedentary behavior, health

Physical activity is associated with multiple health benefits across the life course, ${ }^{1-3}$ Regular activity has been shown to play a role in the primary and secondary prevention of cancer, cardiovascular disease, diabetes, osteoporosis, and obesity. ${ }^{2}$ In addition to these physical health benefits, regular participation in physical activity is associated with a range of positive mental health-related outcomes, ${ }^{4}$ including reduced anxiety, stress, and depression ${ }^{2,5}$ enhanced cognitive function and academic performance. ${ }^{6}$

Despite the health benefits of regular participation, approximately one-third $(31.1 \%)$ of adults are physically inactive. ${ }^{7}$ The transition from adolescence to adulthood, ${ }^{8}$ and in particular the transition to college/university provides an opportunity for influencing adult behavior. ${ }^{9}$ Young adults are exposed to a number of academic, physical, emotional, and social changes ${ }^{10}$ which coupled with changes in independence, and living situations among some students, may influence key health behaviors, such as alcohol use, nutrition, and physical activity. ${ }^{9}$

Physical activity levels decline as adolescents make the transition into adulthood. ${ }^{8,11,12}$ Furthermore, males entering university education may be most at risk from sharp declines in physical activity compared with those not continuing in education. ${ }^{8}$ A metaanalysis has highlighted that $40 \%$ to $50 \%$ of college students are physically inactive. ${ }^{13}$ Although self-reported physical activity

M.H. Murphy, Carlin, and Ferguson are with the School of Sport, Ulster University, Antrim, United Kingdom. Woods and MacDonncha are with the Department of Physical Education and Sport Sciences, University of Limerick, Limerick, Ireland. Nevill is with the School of Sport, Performing Arts and Leisure, University of Wolverhampton, Wolverhampton, United Kingdom. N. Murphy is with the Department of Health, Sport and Exercise Science, Waterford Institute of Technology, Waterford, Ireland. M.H. Murphy (mh.murphy@ulster.ac.uk) is corresponding author. levels of school children and working adults have been welldocumented, ${ }^{7,14}$ there is less information on university students' physical activity engagement, and few are based on representative or random samples. ${ }^{13,15,16}$

In addition to inactivity, the transition to university is associated with increased exposure to other health-risk behaviors, such as poor dietary intake and substance abuse. ${ }^{9}$ Research has indicated that while individuals "grow out" of health-risk behaviors, such as smoking and binge drinking as they progress from adolescence, such positive changes are typically not seen in physical activity behaviors. ${ }^{8}$

Approximately 1 in 5 young adults (aged 19-24 y) in Ireland experience mental health problems. ${ }^{17}$ College students may be at increased risk from mental health disorders, with higher prevalence reported compared with the general population. ${ }^{18}$ Hunt and Eisenberg ${ }^{19}$ report an increase in both the prevalence and severity of mental health disorders among college students. In addition to the negative impact, mental health disorders can have on overall health, such problems may also impact academic performance. ${ }^{20}$

It is well established that regular physical activity can have a positive impact on mental health-related outcomes in adults, ${ }^{4}$ reducing depressive symptoms and improving emotional wellbeing. ${ }^{5,21}$ Evidence has also demonstrated an association between higher levels of physical activity and higher levels of happiness. ${ }^{22}$ Studies in student populations have demonstrated a link between physical activity and reduced symptoms of stress ${ }^{23,24}$ and fewer reports of poor mental health. ${ }^{24}$ Much of this has been in North American populations and focused on vigorous physical activity as opposed to health-enhancing moderate to vigorous physical activity (MVPA). Given the low prevalence of physical activity and high prevalence of mental health problems in young Irish people, the relationship between MVPA and mental health-related outcomes in college students warrants further investigation. 
The increasing proportion of the population now progressing to university-level education is reflective of the transition of Ireland from a middle-income to high-income country between 1987 and $2000 .{ }^{25}$ According to Eurostat data, almost $58 \%$ of Irish women have completed third-level education compared with $44 \%$ of Irish men in 2012, with these levels the highest in Europe. ${ }^{26}$ The potential of colleges to influence uptake and maintenance of physical activity behaviors, and influence other related outcomes, such as mental well-being and happiness, is vast. There is limited data available on the physical activity levels of college students across the island of Ireland, and population surveillance is outlined as a key objective within the National Physical Activity Plan. ${ }^{27}$ Furthermore, the development of a framework for health promoting colleges to include physical activity was included as an action point within the national plan, ${ }^{27}$ highlighting the role that universities and colleges can play in promotion physical activity and other aspects of student well-being.

The aim of this paper was to assess the participation of university students in Ireland in sport and physical activity and to explore to what extent physical activity is associated with overall health, mental health, and happiness.

\section{Methods}

\section{Study Design}

The Student Activity and Sports Participation Survey Ireland (SASSI) was a 3-phase study commissioned by Student Sport Ireland to investigate sports and physical activity participation, preferences, and provision in colleges/universities on the island of Ireland. The methods and results contained within this paper include phase 2 of the study, a cross-sectional analysis of university students across the island of Ireland in 2014-2015. An audit of the environment and institutional provision for sport and physical activity comprised phase 1 , and objective fitness measures were undertaken on a subsample of students in phase 3 .

\section{Sampling}

In order to achieve a nationally representative sample, student data obtained from the Higher Education Academy (Republic of Ireland) ${ }^{28}$ and Department of Employment and Learning (Northern Ireland), ${ }^{29}$ enrollments within each institution were categorized into 10 "fields of study." In each institution, random sampling of student groups was undertaken in proportion to the numbers of students studying at each year of study (including undergraduate and postgraduate) within each "field of study." Once the sampling framework was applied to identify groups of students by year and field of study, all students attending the selected class were eligible for inclusion. A total of 41 higher education institutions were contacted to participate in the phase 2 SASSI student survey. Of this, 31 institutions responded, 4 declined to participate, 5 did not respond to contact, and 1 used an unapproved protocol (e-mailing the survey link to all students in the institution). From the 31 participating institutions, the total quota sought was 10,606 .

\section{Study Procedure}

Each institution assigned a "SASSI champion" who was trained to facilitate recruitment and data collection. The SASSI champion was provided with a list of randomly selected class groups within their institution and sought permission from teaching staff within their institution to access the group during class time, either before the lecturer commenced or at the end of the lecture before the students were dismissed. In order to maximize response, the online survey was administered through SurveyMonkey (San Mateo, CA) to the entire class group (chosen using an online random number generator) in the appropriate year group and field of study during a timetabled hour. Surveys were either completed by students using a computer suite on campus or by using their own devices during regular (noncomputer-based) classes. Students were not able to access and complete the survey remotely using a web link to reduce the likelihood of self-selection bias.

The survey took approximately 20 minutes to complete. All surveys were completed between October and December 2014. The institutional champion introduced the survey outlining the objectives and assuring anonymity of responses. Survey completion was incentivized within each institution by entry into a prize draw could be exchanged for purchases at a range of retail stores or food outlets. The value of the prize varied by institution but was on average $€ 100$. One prize was provided by each institution. In order to verify that sampling by the champion took place as directed, the date stamps of responses was examined for each institution. Where the majority $(>90 \%)$ of responses occurred in batches and within normal college hours, it was deemed likely that the survey administration protocol was adhered to.

\section{Student Survey}

The student survey was developed to assess students' participation in sport and physical activity, perception of the institutional sports and physical activity environment, the enablers and barriers to participation (correlates), performance support for high-level and scholarship athletes, related health behaviors, and other demographics. Survey items were derived, where possible, from existing validated instruments. Items were selected in consultation with the Student Sport Ireland Research Management Group, and advice was sought from 3 international experts with considerable expertise in the design and analysis of physical activity surveys. The survey was piloted among members of the research team, SASSI champions, and students in 4 participating institutions, and amended accordingly based on feedback.

Ethical approval was granted by Ulster University and recognized by all participating institutions. Where this was not possible, champions sought local ethical approval for the study from their institution's ethics committee.

\section{Outcome Measures}

\section{Demographics}

Sociodemographic information included student background information (age and gender, field and year of study, full-time or part-time) and other demographics (ethnicity, marital status, socioeconomic class, employment, and accommodation).

\section{Physical Activity Behaviors}

Physical activity was measured using the International Physical Activity Questionnaire-Short Form (IPAQ-SF), ${ }^{30}$ shown to be a valid and reliable measure of physical activity in this population. ${ }^{31,32}$ Using the IPAQ scoring protocol, participants were categorized as "high," "moderate," or "low" active, ${ }^{33}$ with 
individuals categorized as "high" active being deemed as meeting minimum physical activity requirements. ${ }^{34}$ Participation in muscle strengthening activities was assessed using tools from the Children's Sport Participation and Physical Activity Young Adult Study. ${ }^{35}$ Student's knowledge of the physical activity guidelines was assessed using a modified question from the Health Survey for England. ${ }^{36}$ Mode of transport to college/university was assessed using a single-item tool previously used in the Children's Sport Participation and Physical Activity Young Adult Study. ${ }^{35}$ In addition to overall levels physical activity, students were asked about their participation in a range of organized sports and recreational physical activities. Respondents selected up to 5 activities and indicated the frequency, duration, and intensity of these activities and whether they took place within and outside the college setting.

\section{Sedentary Behavior}

Domain-specific sedentary behavior was measured using a modified version of an instrument which has been assessed for genderspecific test-retest reliability and validity. ${ }^{37}$ The instrument required participants to estimate time spent sitting on weekdays and weekend days across 8 domains (attending class, while studying, for transport, at work, using a computer, using a smartphone/ tablet, watching television, and during leisure time). Time spent sitting in each domain was summed together to provide an overall daily total for hours spent in sedentary behavior.

\section{Body Mass Index}

Body mass index (BMI, $\mathrm{kg} \cdot \mathrm{m}^{-2}$ ) was calculated using self-reported height and weight. Students were classified as underweight $(<18.5)$, normal weight $(18.5 \leq \mathrm{BMI}<25)$, overweight $(25 \leq$ BMI $<30)$, or obese $(\geq 30)$ according to World Health Organization references values. ${ }^{38}$

\section{Self-Rated Overall Health}

Self-rated overall health was assessed using an item from the Short Form Health Survey (SF-36). ${ }^{39}$ which asked respondents to rate their health over the past 12 months on a 5-point scale. Responses were dichotomized by grouping those reporting either average, poor, or very poor health, and those reporting very good or good health together.

\section{Happiness}

Happiness was assessed on a 10-point Likert scale adapted from the Sport and Physical Activity Survey. ${ }^{40}$ Responses were dichotomized into those with a score below 7 (the median average for happiness) and those with a score of 7 or above (happy). ${ }^{41}$

\section{Mental Health}

Mental health was assessed using the Mental Health Index, adopted from the SF-36 questionnaire. ${ }^{39}$ A single score was calculated for mental health from a 5-item index. Those with a score equal to or below the recommended cutoff score of 52 were identified as having a "probable mental health problem," 42 while a score above 52 was indicative of higher levels of positive mental health and well-being.

\section{Data Analysis}

Data analysis was conducted using IBM SPSS Statistics (version 22; SPSS Inc, Chicago, IL). Descriptive statistics were derived to describe and summarize the dataset. Pearson's chi-squared tests of independence were applied to investigate the association between meeting the physical activity guidelines and gender and year of study. Binary logistic regressions were performed to examine the associations between self-reported physical activity (meeting the guidelines, moderately active or inactive); gender; and individual perceptions of health, mental health, and happiness. Binary outcome variables were health, mental health, and happiness, and the predictor variables were level of physical activity and gender. Probability was set at $P<.05$.

\section{Results}

\section{Response Rate}

A total of 31 colleges participated in the student survey. Of this, 14 colleges achieved their target quota, 12 fell slightly below (within $10 \%$ ) their target quota, and 5 colleges exceeding their target. Given that the study focused on physical activity and sport, respondents who did not complete any questions focused on physical activity were regarded as nonresponders and removed from subsequent analysis. In total, 9197 survey responses were collected, representing $87 \%$ of the target quota. Following the removal of nonresponders, 8122 survey responses were included in the analysis.

\section{Demographics}

The demographics of participants are in Table 1. Approximately half $(50.9 \%)$ of respondents were females. The mean age of the sample was 23.17 years $(\mathrm{SD}=6.75)$. The majority of participants were from a White ethnic background (91.2\%), with other ethnicities including Asian (4.3\%), Black (1.9\%), mixed/multiple (1.6), and other $(1.1 \%)$. Respondents were mainly undergraduate students $(92.4 \%)$ enrolled in full-time courses $(94.1 \%)$. Based on selfreported height and weight, $65.4 \%$ of respondents were classified as "healthy weight" (BMI score between 18.5 and 24.9; Table 1).

\section{Physical Activity Levels}

Only $64.3 \%$ of participants met the minimum physical activity guidelines of 150 minutes MVPA per week and $27.5 \%$ of participants were classified as "moderately active," while $8.1 \%$ of participants were classified as inactive. Pearson's chi-squared tests indicated that males $(71.2 \%)$ were more likely to be meeting the guidelines compared with females $(57.8 \%), \chi^{2}(2, \mathrm{n}=7421)=0.139$; $P<.001$; Figure 1 . There were no differences in the proportion of students meeting the guidelines across each year of university $(P=.31) ; 50.1 \%$ of females, and $31.9 \%$ of males reported undertaking no muscle strengthening activities in the past week.

Approximately one-third $(31.8 \%)$ of respondents felt that they were not undertaking "enough physical activity to keep healthy." A significant difference was observed between genders $(24.2 \%$ of males compared with $38.9 \%$ of females, $P<.001)$. Over one-quarter of students classified as inactive felt that they were sufficiently active for their health. Approximately one-third of respondents (35.7\%) felt they were doing the same level of activity as this time last year, with $30.9 \%$ reporting doing more activity and $30.7 \%$ reporting doing less activity.

Approximately $31.5 \%$ of respondents correctly identified the physical activity guidelines as "a minimum of 30 minutes of 
Table 1 Demographics

Overall, N (\%)

Male, N (\%)

Female, $\mathbf{N}(\%)$

\begin{tabular}{c}
\hline Gender \\
Female \\
Male \\
Age range \\
$18-25$ \\
$26-35$ \\
$>35$
\end{tabular}

Body mass index

Underweight

Healthy weight

Overweight

Obese

Course of study

Undergraduate

Postgraduate

Mode of study

Full-time

Part-time

Field of study

Humanities and arts

Social sciences, business and law

Education (and teacher training)

Science, mathematics and computing

Engineering, manufacturing and construction

Agriculture and veterinary

Health and welfare (including nursing, health promotion, physiotherapy)

Travel tourism and leisure

Sports, exercise science-related courses

Other

Accommodation

College/university halls of residence (on campus)

College/university halls of residence (off campus)

Rented privately

Family home

Other

Employment

Full time

Part time

Not working
4112 (50.9)

3966 (49.1)

$6215(81.6)$

893 (11.7)

506 (6.7)

366 (6.1)

3904 (65.4)

1267 (21.2)

437 (7.3)

$7501(92.4)$

$621(7.6)$

7460 (94.1)

471 (5.9)

1168 (14.6)

1692 (21.2)

387 (4.9)

2050 (25.7)

$582(7.3)$

107 (1.3)

$940(11.8)$

93 (1.2)

498 (6.2)

463 (5.8)

603 (9.6)

455 (7.2)

2105 (33.4)

2984 (47.3)

603 (9.6)

426 (6.7)

2928 (46.1)

2998 (47.2)
2987 (80.6)

481 (13.0)

238 (16.4)

$152(5.2)$

1874 (63.7)

708 (24.1)

206 (7.0)

3700 (93.3)

$266(6.7)$

3675 (94.8)

$203(5.2)$

403 (10.3)

693 (17.7)

$91(2.3)$

1417 (36.2)

446 (11.4)

54 (1.4)

$230(5.9)$

$27(0.7)$

356 (9.1)

193 (4.9)

$238(7.8)$

202 (6.6)

1001 (32.7)

1562 (50.9)

$63(2.1)$

205 (6.6)

1301 (42.0)

1592 (51.4)
3197 (82.6)

407 (10.5)

$268(6.9)$

214 (7.1)

2010 (66.8)

554 (18.4)

$230(7.6)$

3758 (91.4)

353 (8.6)

3746 (93.3)

268 (6.7)

761 (18.9)

996 (24.7)

295 (7.3)

$617(15.3)$

130 (3.2)

$53(1.3)$

704 (17.5)

66 (1.6)

$138(3.4)$

$270(6.7)$

$361(11.3)$

$250(7.8)$

$1096(34.2)$

1408 (43.8)

$95(3.0)$

$221(6.8)$

$1612(50.0)$

1394 (43.2) physical activity per day," while $1.5 \%$ correctly identified "at least 150 minutes per week of MVPA" as the volume and intensity of physical activity recommended to gain the associated health benefits. Females $(39.3 \%)$ were significantly more knowledgeable about the physical activity guidelines than males $(26.3 \%)(P=.01)$.

Approximately $40.3 \%$ of respondents stated that they actively commuted to college, either by foot $(34.05)$ or bicycle $(6.35 \%)$. Approximately one-third (32.6\%) of students usually traveled to college by car. Just over a quarter of respondents $(26.8 \%)$ usually travelled to college using public transport, such as bus (19.6\%) or train/tram $(7.2 \%)$.

\section{Sporting and Recreational Physical Activity Participation}

Approximately one-third (34.8\%) of respondents did not participate in any sporting or recreational activity in the last 4 weeks. Differences between genders were also observed, with $28.4 \%$ of males not participating compared with $40.9 \%$ of females (Figure 2 ). The lowest levels of participation were within college, where only $14.3 \%$ of respondents played sport, $18.3 \%$ participated inside and outside of college, and $32.5 \%$ reported participating only through outside organizations and facilities. 


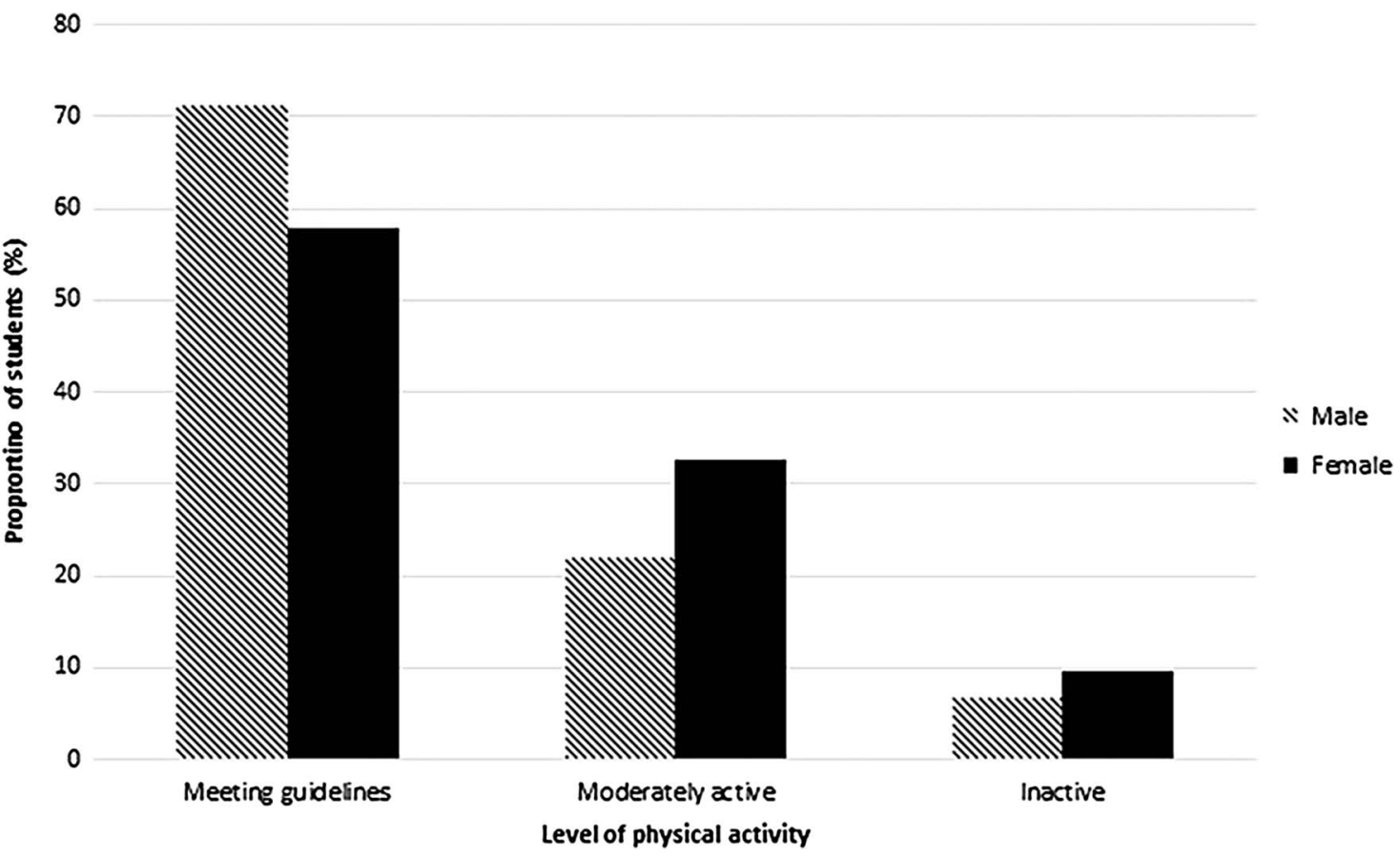

Figure 1 - Proportion of male and female students meeting the physical activity guidelines.

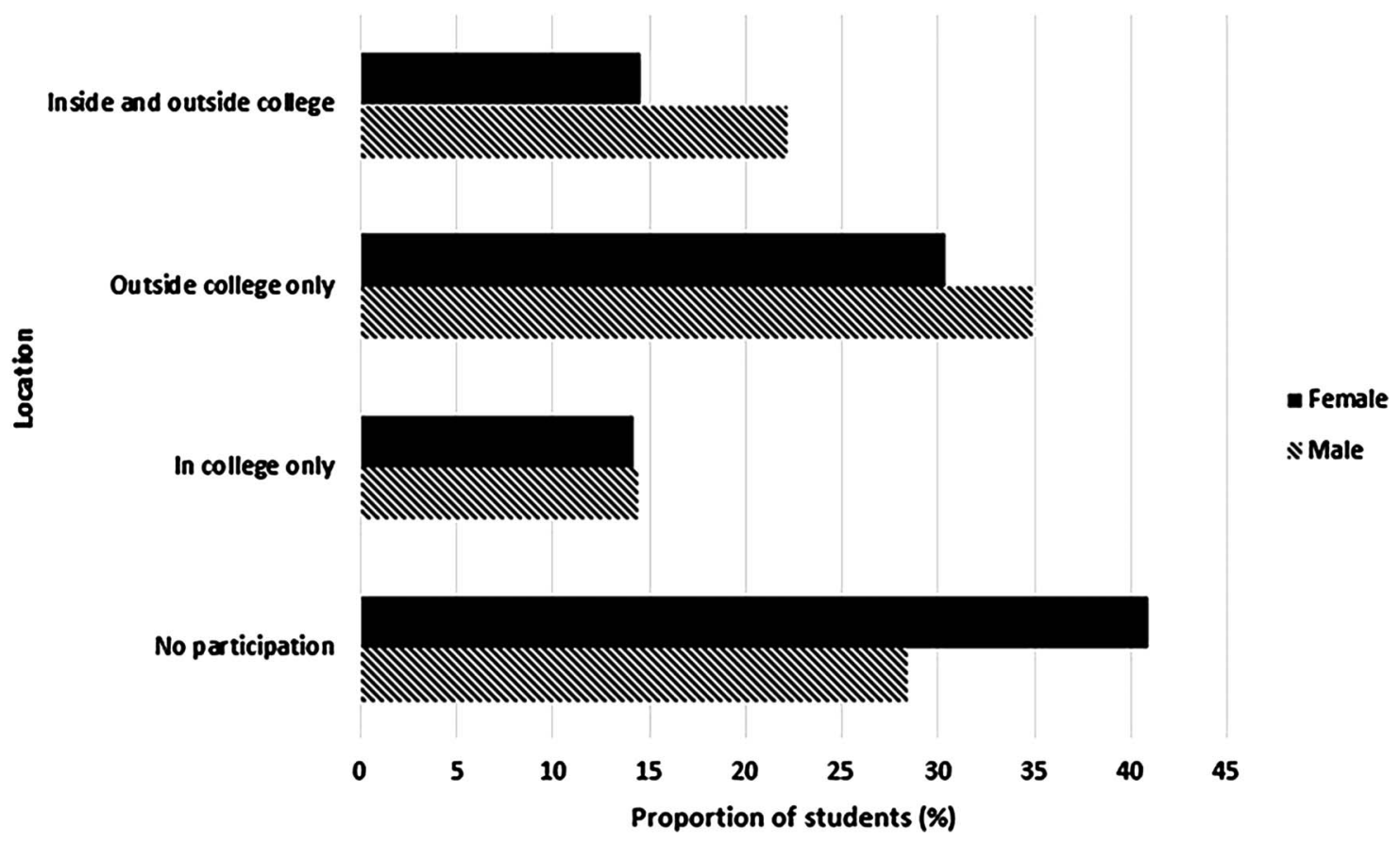

Figure 2 - Sport and physical activity participation by location.

Weight training or cardio workouts were the most popular activities undertaken by respondents across all settings (ie, inside and outside of college). Weight training, cardio workout, and walking were identified as the 3 most popular activities undertaken within the college setting. Of the top 13 sports identified within college, 10 were individual activities (eg, walking, running, swimming, etc).

\section{Sedentary Behavior}

Respondents reported, on average, spending 12.1 hours (SD = 7.37) per weekday engaged in sedentary behaviors (studying, attending class, watching television, using computers, etc), compared with 10.1 hours $(\mathrm{SD}=8.67)$ on weekends. A higher proportion of respondents reported spending at least 8 hours per day 
engaged in sedentary behaviors on weekdays (71.2\%) compared with weekends $(55.8 \%)$. Television viewing, computer use, and smartphone use were the largest contributors to overall sedentary time. Male students reported more noneducation-related sedentary screen time than females on both weekdays $\left(4.3 \mathrm{vs} 3.6 \mathrm{~h} \cdot \mathrm{d}^{-1}\right)$ and weekends (5.3 vs $\left.4.4 \mathrm{~h} \cdot \mathrm{d}^{-1}\right)(P<.01)$.

\section{Associations Between Level of Physical Activity and Health-Related Outcomes}

Perceived General Health. The majority of respondents (55.6\%) reported their health as good or very good (Table 2). Those meeting the physical activity guidelines were 2.2 times more likely to report good or very good health than those classified as inactive (95\% confidence interval $[\mathrm{CI}], 1.839-2.712 ; P<.001$; Table 3). Furthermore, those classified as "moderately" active were $35.6 \%$ more likely to report good or very good healthy (95\% CI, 1.104-1.666; $P=.004)$. Males were $22.9 \%$ more likely to report good or very good health compared with females (95\% CI, 1.109-1.361; $P<.001$; Table 3).

Mental Health. The overall mean mental health score for respondents was $66.7(\mathrm{SD}=19.96)$. Based on the cut point of a mental health score $\leq 52,22.7 \%$ of students were categorized as having a "probable mental health problem" (Table 2). Those meeting the physical activity guidelines were $55 \%$ more likely to report better mental health than those classified as inactive (95\% CI, 1.5421.916; $P<.001$; Table 4). Those classed as "moderately" active were $23 \%$ more likely to report better mental health; however, this difference was not significant (95\% CI, 0.983-1.541; $P=.07$ ). Males were also $23.3 \%$ more likely to report better mental health compared with females (95\% CI, 1.092-1.392; $P=.001$; Table 4).

Happiness. The majority of respondents (64.7\%) reported a high level of happiness (indicated by a score of 7 or above; Table 2). Those meeting the physical activity guidelines were 2.2 times more likely to report feeling happy than those classified as inactive (95\% CI, 1.828-2.693; $P<.001$; Table 5). Those classified as "moderately" active were $46.6 \%$ more likely to report higher happiness $(95 \% \mathrm{CI}, 1.195-1.799 ; P<.001)$. No significant gender differences were observed for the association between physical activity level and reported happiness (95\% CI, 0.954-1.181; $P=.28$; Table 5).

Table 2 Health-Related Characteristics

\begin{tabular}{lccc}
\hline & Overall, N (\%) & Male, N (\%) & Female, N (\%) \\
\hline General health & & & \\
Very good & $1001(15.7)$ & $547(17.6)$ & $447(13.8)$ \\
Good & $2543(39.9)$ & $1291(41.5)$ & $1238(38.4)$ \\
Average & $2128(33.4)$ & $971(31.2)$ & $1152(35.7)$ \\
Poor & $556(8.7)$ & $237(7.6)$ & $317(9.8)$ \\
Very poor & $125(2.0)$ & $56(1.8)$ & $69(2.1)$ \\
Do not know & $13(0.2)$ & $8(0.3)$ & $6(0.2)$ \\
Mental health & & & \\
Poor & $1441(22.7)$ & $639(20.8)$ & $796(24.6)$ \\
Good & $4905(77.3)$ & $2441(79.2)$ & $2441(75.4)$ \\
Happiness & & & \\
Happy & $4076(64.7)$ & $2028(66.2)$ & $2027(63.1)$ \\
Unhappy & $2228(35.3)$ & $1035(33.8)$ & $1187(36.9)$ \\
\hline
\end{tabular}

Table 3 Differences in Perceived General Health (Very Good, Good) due to Physical Activity Level and Gender

\begin{tabular}{lccc}
\hline & Model 1 & & \\
\cline { 2 - 3 } & $\begin{array}{c}\text { Odds } \\
\text { ratio }\end{array}$ & $\begin{array}{c}\text { 95\% confidence } \\
\text { interval }\end{array}$ & $\begin{array}{c}\boldsymbol{P} \\
\text { value }\end{array}$ \\
\hline $\begin{array}{l}\text { Physical activity level } \\
\text { Inactive }\end{array}$ & 1.00 & & \\
$\quad \begin{array}{l}\text { Moderately active } \\
\text { Meeting }\end{array}$ & 1.356 & $1.104-1.666$ & .004 \\
guidelines & 2.233 & $1.839-2.712$ & $<.001$ \\
$\begin{array}{l}\text { Gender } \\
\text { Female }\end{array}$ & & & \\
$\quad$ Male & 1.00 & & $<.001$ \\
Constant & 1.229 & $1.109-1.361$ & \\
\hline
\end{tabular}

Table 4 Differences in Perceived Mental Health due to Physical Activity Level and Gender

\begin{tabular}{lccc}
\hline & Model 1 & & \\
\cline { 2 - 3 } & $\begin{array}{c}\text { Odds } \\
\text { ratio }\end{array}$ & $\begin{array}{c}\text { 95\% confidence } \\
\text { interval }\end{array}$ & $\begin{array}{c}\boldsymbol{P} \\
\text { value }\end{array}$ \\
\hline $\begin{array}{l}\text { Physical activity level } \\
\text { Inactive }\end{array}$ & 1.00 & & \\
$\quad$ Moderately active & 1.231 & & \\
$\quad$ Meeting & 1.550 & $1.254-1.916$ & $<.001$ \\
guidelines & & & \\
Gender & & & \\
$\quad$ Female & 1.00 & & .001 \\
$\quad$ Male & 1.233 & $1.092-1.392$ & \\
Constant & 2.230 & & \\
\hline
\end{tabular}

Table 5 Differences in Happiness due to Physical Activity Level and Gender

\begin{tabular}{lcccc}
\hline & Model 1 & & \\
\cline { 2 - 3 } & $\begin{array}{c}\text { Odds } \\
\text { ratio }\end{array}$ & $\begin{array}{c}\text { 95\% confidence } \\
\text { interval }\end{array}$ & $\begin{array}{c}\boldsymbol{P} \\
\text { value }\end{array}$ \\
\hline $\begin{array}{l}\text { Physical activity level } \\
\text { Inactive }\end{array}$ & 1.00 & & \\
$\quad \begin{array}{l}\text { Moderately active } \\
\text { Meeting }\end{array}$ & 1.466 & $1.195-1.799$ & $<.001$ \\
guidelines & 2.219 & $1.828-2.693$ & $<.001$ \\
Gender & & & \\
$\quad$ Female & & & \\
$\quad$ Male & 1.00 & & \\
Constant & 1.061 & $0.954-1.181$ & \\
\hline
\end{tabular}

\section{Discussion}

The aim of this paper is to assess the participation of university/ college students in sport and physical activity in Ireland and to explore whether physical activity is associated with health, mental health, and happiness. 
In this study, $64.3 \%$ of participants $(72.1 \%$ males and $57.8 \%$ females) met the minimum physical activity guidelines of 150 minutes MVPA per week. Recent population level data from the Healthy Ireland Survey reported 56\% of men aged 15-24 years were achieving the physical activity guidelines, decreasing to $52 \%$ of men aged 25-34 years. ${ }^{43}$ Consistent with SASSI findings, females in the general population were less likely to meet the guidelines than males, with $34 \%$ of women aged 15-24 years and $32 \%$ aged $25-34$ years meeting the guidelines. ${ }^{43}$ These data highlight that university/college students in Ireland, particularly females, are considerably more active than their counterparts in the general population. In addition to the guideline for levels of MVPA, the SASSI survey also highlighted low levels of muscle strengthening activities, with $50.1 \%$ of females and $31.9 \%$ of males reported undertaking no muscle strengthening activities in the past week.

Approximately one-third of students (35.7\%) were not meeting the physical activity guidelines within the SASSI survey. A previous meta-analysis by Keating et al $^{13}$ highlighted inactivity levels in the range of $40 \%$ to $50 \%$ among students, which is higher than the levels reported in the present study. Data across other countries have reported varying levels of inactivity among college students, with approximately half of students in the United States and Canada and approximately $40 \%$ of Australian students not meeting the guidelines for physical activity. ${ }^{16}$ More recent data from Pengpid et $\mathrm{al}^{44}$ have highlighted the wide variation, with the proportion of undergraduate college students categorized as inactive ranging from $22 \%$ to $81 \%$ across 23 countries. The significant gender differences reported within the SASSI survey are consistent with previous research. ${ }^{45}$

Some of the inconsistencies in inactivity levels observed across studies may be attributed to the different measures employed within studies to measure physical activity levels. ${ }^{32}$ Research by Downs et $\mathrm{al}^{46}$ demonstrated that the use of the IPAQ may overestimate levels of MVPA by up to 45 minutes per day compared with accelerometer-derived data. Within the SASSI study, moderate correlations were found between the IPAQ and accelerometerderived levels of MVPA, indicating that is a suitable tool for measuring physical activity among college students, ${ }^{32}$ consistent with previous findings. ${ }^{31}$

The present study also assessed levels of sedentary behavior among students, highlighting that a greater proportion of students were engaged in at least 7 hours per day of sedentary behavior during weekdays (72.3\%) compared with weekends (55.8\%). Accelerometer-derived sedentary behavior has highlighted similar high levels of sedentary behavior among UK adults. ${ }^{47}$ Data on selfreported sitting time among the general population in Ireland indicated that young people aged 15 to 24 years spent the most time sitting $\left(6.3 \mathrm{~h} \cdot \mathrm{d}^{-1}\right)$, with females aged 15 to 24 years found be the most. ${ }^{48}$ No significant differences were observed between genders within the present study. A review of the evidence from 3 systematic reviews concluded that although the heterogeneity of the measures used in studies of sitting and health outcomes make it difficult to draw conclusions about dose-response relationships, the data suggest that those who sit for $>8$ hours per day have significant health risk. ${ }^{49}$ With mean self-reported sedentary time of 12.1 hours on weekdays and 10.1 hours on weekend days, it is clear that this population of students are likely to be damaging their health through excessive time spent in sedentary pursuits.

Research to date on the relationship between physical activity and sedentary behaviors among college students has been inconsistent. ${ }^{50}$ However, a number of correlates have been identified, for example, individual factors, social networks, the physical environment, and advertising and media, which may influence both behaviors in college students. ${ }^{50}$ Educational institutions present an ideal vehicle for lifestyle interventions to promote physical activity and reduce sedentary behaviors among university students. ${ }^{51}$ Access to resources, health care professionals and research expertise, within a learning environment, provides an ideal platform for influencing and changing health behaviors in this population. ${ }^{51}$ Given the observed levels of inactivity and sedentary behavior within the present study, further research is warranted to further explore the determinants of physical activity and the role of interventions in favorably changing health behaviors among college students.

Over half of students $(55.6 \%)$ reported their general health as very good/good within the present study. The results observed within the SASSI survey are significantly lower compared with other college cohorts; for example, $92.3 \%$ of American students reported their health to be excellent, very good, or good in the National College Health Assessment II study. ${ }^{52}$ Previous studies among the general population in Ireland have also reported higher ratings; $88 \%$ of adults in the SLÁN survey ${ }^{53}$ and $92 \%$ of $15-$ to $24-$ year-old adults in the Healthy Ireland Survey. ${ }^{48}$ Given the lower ratings observed within the present study and the range of variables that may impact upon student health, for example, mood, social support, and sleeping habits, ${ }^{54}$ the overall health of college students and the determinants influencing student health warrants further investigation.

Within the SASSI study, respondents who reported meeting the physical activity guidelines were twice as likely to report feeling healthy as those classified as inactive, with males $22.9 \%$ more likely to report feeling healthy compared with females. Meeting the physical activity guidelines for MVPA has been previously shown to be positively associated with a positive perception of general health status among American college students, ${ }^{52}$ highlighting the association between physical activity and protective health factors.

The average mental health score of students within the SASSI study was 66.7, again representing a deviation from the general population where mean scores were reported as 86.3 and 81.6 for males and females aged 15-24 years respectively. ${ }^{48}$ A previous study in a smaller sample of Irish students $(n=1000)$ recorded a mean score of 72.6.55 The observed differences in mental health scores among students compared with the general young adult population may be attributable to personal, developmental, and social issues, coupled with the pressures of combining study and paid employment. ${ }^{55}$ Furthermore, the changing landscape of thirdlevel education may diminish some of the protective factors against developing mental health problems during college. ${ }^{56}$ Increased student numbers, larger class sizes, and reduced personal support from academic staff may impact upon student experiences in relation to making friends and developing a sense of belonging. ${ }^{56}$

Meeting the physical activity guidelines was also associated with higher mental health scores among respondents within the SASSI survey, with those meeting the guidelines 55\% more likely to report better mental health than those classified as inactive. Males were also $23.3 \%$ more likely to report better mental health compared with females. Depressive symptoms have previously been highlighted as a risk factor for physical inactivity among college students. ${ }^{44}$ The associations observed between physical activity and mental health are consistent with previous research in college students. Students meeting the recommendations for vigorous physical activity have been shown to be more likely report 
positive mood profiles (lower fatigue and higher vigor) ${ }^{10}$ and have reduced depressive symptoms ${ }^{23}$ compared with their inactive peers. The gender differences observed within the SASSI survey reflect the consensus that female students are more likely to report and screen positive for major anxiety disorders and depression. ${ }^{19}$ Given the prevalence of mental health disorders and suicide rates, particularly among young Irish males, ${ }^{57}$ third-level institutions have a duty to promote mental health and well-being. ${ }^{19}$ Hassles, such as "academic bureaucracy," "family expectations," and "financial security" have been shown to have a negative impact on physical activity levels and may represent avenues that third-level institutions can target to reduce distress, and subsequently improve physical activity behaviors among students. ${ }^{58}$ Furthermore, the promotion of physical activity, and physical self-esteem, among students may play a role in improving overall quality of life. ${ }^{59}$

There is currently a paucity of data examining the relationship between happiness and health-related behaviors in college students. Limited evidence has suggested a possible role for physical activity in improving levels of happiness. ${ }^{22}$ The majority of respondents within SASSI reported high levels of happiness, with those meeting the physical activity guidelines twice as likely to report feeling happier than those classified as inactive. A crosssectional study of European countries highlighted a positive doseresponse relationship between happiness and physical activity levels. ${ }^{22}$ A survey among Chilean students found a moderate association between daily, regular exercise and happiness. ${ }^{60}$ Promoting the potential role of physical activity on overall well-being, including mental health and happiness, may play a role in engaging students in positive health behaviors.

There are a number of limitations that should be taken into consideration when interpreting the findings of this study. A crosssectional survey design was undertaken; therefore, casual relationships between physical activity and health, mental health, and happiness cannot be drawn. Physical activity was measured using a self-report instrument, yet this was validated in a subsample of participants. ${ }^{32}$ Health, mental health, and happiness were dichotomized based on self-reported perceptions. Future studies should seek to further explore the reported associations through the use of objective measurement tools (pedometers, accelerometers) and objective measures of assessing physical activity-related outcomes.

\section{Conclusions}

The SASSI study is the first representative, large-scale survey of student physical activity and sport participation across Ireland. This research provides a baseline marker for physical activity levels and sedentary behavior among university students, which will allow for future monitoring and evaluation of interventions and policy changes. The observed associations between health-enhancing levels of physical activity and health-related outcomes, such as general health, mental health, and happiness have been previously understudied in this population and warrant further investigation within studies employing objective measures and longitudinal design. Active college students enjoy better health and are happier than their inactive peers. College represents a key period to engage and influence numerous health behaviors among young adults, and the role that physical activity can play in improving both physical and mental well-being should not be overlooked by third-level institutions as they seek to improve student well-being. The findings of the study should help policymakers within and outside the third-level education sector to determine the most appropriate target groups for physical activity interventions and determine which interventions might hold the most promise for increasing activity. In addition, both the methodology and the findings provide a useful comparator for other countries wishing to monitor physical activity in this college-aged population.

\section{Acknowledgments}

Joey Murphy (DCU, UL), Neal Byrne (WIT) and the SASSI champions for data collection. This study was funded by Student Sport Ireland.

\section{References}

1. Hallal PC, Victoria CG, Azevedo MR, Wells JC. Adolescent physical activity and health: a systematic review. Sports Med. 2006;36(12):10191030. PubMed ID: 17123326 doi:10.2165/00007256-200636120-00003

2. Warburton D, Nicol C, Bredin S. Health benefits of physical activity: the evidence. CMAJ. 2006;174(6):801-809. PubMed ID: 16534088 doi:10.1503/cmaj.051351

3. Lee IM, Shiroma EJ, Lobelo F, et al. Effect of physical inactivity on major non-communicable diseases worldwide: an analysis of burden of disease and life expectancy. Lancet. 2012;380(9838):219-229. PubMed ID: 22818936 doi:10.1016/S0140-6736(12)61031-9

4. Pendeo F, Dahn J. Exercise and well-being: a review of mental and physical health benefits associated with physical activity. Curr Opin Psychiatry. 2005;18(2):189-193. doi:10.1097/00001504-20050300000013

5. Conn VS. Depressive symptom outcomes of physical activity interventions: meta-analysis findings. Ann Behav Med. 2010;39(2):128138. PubMed ID: 20422333 doi:10.1007/s12160-010-9172-x

6. Gomez-Pinilla F, Hillman C. The influence of exercise on cognitive abilities. Compr Physiol. 2013;3(1):403-428. PubMed ID: 23720292

7. Hallal P, Andersen LB, Bull F, et al. Global physical activity levels: surveillance progress, pitfalls, and prospects. Lancet. 2012;380(9838): 247-257. PubMed ID: 22818937 doi:10.1016/S0140-6736(12)60646-1

8. Kwan MY, Cairney J, Faulkner GE, Pullenayegum EE. Physical activity and other health-risk behaviors during the transition into early adulthood: a longitudinal cohort study. Am J Prev Med. 2012;42(1):14-20. PubMed ID: 22176841 doi:10.1016/j.amepre.2011.08.026

9. Nelson MC, Lust K, Story M, Ehlinger E. Alcohol use, eating patterns, and weight behaviors in a University population. Am J Health Behav. 2009;33(3):227-237. PubMed ID: 19063644 doi:10. 5993/AJHB.33.3.1

10. Bray S, Born H. Transition to university and vigorous physical activity: implications for health and psychological well-being. $J$ Am Coll Health. 2004;52(4):181-188. PubMed ID: 15018429 doi:10.3200/JACH.52.4.181-188

11. Caspersen C, Pereira M, Curran K. Changes in physical activity patterns in the United States, by sex and cross-sectional age. Med Sci Sports Exerc. 2000;32(9):1601-1609. PubMed ID: 10994912 doi:10. 1097/00005768-200009000-00013

12. Telama R, Yang X. Decline of physical activity from youth to young adulthood in Finland. Med Sci Sports Exerc. 2000;32(9):1617-1622. PubMed ID: 10994914 doi:10.1097/00005768-200009000-00015

13. Keating X, Guan J, Pinero J, Bridges D. A meta-analysis of college students' physical activity behaviors. J Am Coll Health. 2005;54(2): 116-125. PubMed ID: 16255324 doi:10.3200/JACH.54.2.116-126

14. Kalman M, Inchley J, Sigmundova D, et al. Secular trends in moderate-to-vigorous physical activity in 32 countries from 2002 to 2010: a cross-national perspective. Eur J Public Health. 2015;25:37-40. PubMed ID: 25805785 doi:10.1093/eurpub/ckv024 
15. Wallace L, Buckworth J, Kirby T, Sherman W. Characteristics of exercise behavior among college students: application of social cognitive theory to predicting stage of change. Prev Med. 2000;31(5):494505. PubMed ID: 11071829 doi:10.1006/pmed.2000.0736

16. Irwin J. Prevalence of university students' sufficient physical activity: a systematic review. Percept Mot Skill. 2004;98(3):927-943. doi:10. 2466/pms.98.3.927-943

17. Cannon M, Coughlan H, Clarke M, Harley M, Kelleher I. The Mental Health of Young People in Ireland: A Report of the Psychiatric Epidemiology Research Across the Lifespan (PERL) Group. Dublin, Ireland: Royal College of Surgeons in Ireland; 2013.

18. Adlaf E, Gliksman L, Demers A, Newton-Taylor B. The prevalence of elevated psychological distress among Canadian undergraduates: findings from the 1998 Canadian Campus Survey. J Am Coll Health. 2001;50(2): 67-72. PubMed ID: 11590985 doi:10.1080/07448480109596009

19. Hunt J, Eisenberg D. Mental health problems and help-seeking behavior among college students. J Adolesc Health. 2010;46(1): 3-10. PubMed ID: 20123251 doi:10.1016/j.jadohealth.2009.08. 008

20. Eisenberg D, Downs MF, Golderstein E, Zivin K. Stigma and help seeking for mental health among college students. Med Care Res Rev. 2009;66(5):522-541. PubMed ID: 19454625 doi:10.1177/ 1077558709335173

21. Galper D, Trivedi M, Barlow C, Dunn A, Kampert J. Inverse association between physical inactivity and mental health in men and women. Med Sci Sports Exerc. 2006;38(1):173-178. PubMed ID: 16394971 doi:10.1249/01.mss.0000180883.32116.28

22. Richards J, Jiang X, Kelly P, Chau J, Bauman A, Ding D. Don't worry, be happy: cross-sectional associations between physical activity and happiness in 15 European countries. BMC Public Health. 2015;15:53. PubMed ID: 25636787 doi:10.1186/s12889-015-1391-4

23. Harbour VJ, Behrens TK, Kim HS, Kitchens CL. Vigorous physical activity and depressive symptoms in college students. $J$ Phys Act Health. 2008;5(4):516-526. PubMed ID: 18648117 doi:10.1123/ jpah.5.4.516

24. Vankim NA, Nelson TF. Vigorous physical activity, mental health, perceived stress, and socializing among college students. Am J Health Promot. 2013;28(1):7-15. PubMed ID: 23470187 doi:10.4278/ajhp. 111101-QUAN-395

25. Foxley A, Sossford F. Making the transition: from middle-income to advanced economies. Carnegie Endowment for International Peace. 2011. http://carnegieendowment.org/files/making_the_transition.pdf. Accessed April 15, 2017.

26. European Commission. Third-level education attainment. Eurostat. 2013. http://ec.europa.eu/eurostat/. Accessed April 17, 2017.

27. Healthy Ireland. Get Ireland active! National Physical Activity plan for Ireland. 2016. http://www.getirelandactive.ie/Professionals/NationalPA-Plan.pdf. Accessed April 15, 2017.

28. Higher Education Academy. Key facts and figures higher education 2011/12. 2013. http://hea.ie/resource-year/2013/publications/. Accessed April 12, 2017.

29. Department for Employment and Learning. Statistical bulletin: enrolments at UK higher education institutions: Northern Ireland analysis 2012/13. 2013. https://www.economy-ni.gov.uk/publications/ enrolments-uk-higher-education-institutions-northern-ireland-analysis2012-2013. Accessed April 3, 2017.

30. Craig C, Marshall A, Sjostrom M, et al. International physical activity questionnaire: 12-country reliability and validity. Med Sci Sports Exerc. 2003;35(8):1381-1395. PubMed ID: 12900694 doi:10.1249/ 01.MSS.0000078924.61453.FB

31. Dinger MK, Han JL, Behrens TK. Validity and reliability of the international physical activity questionnaire in college students. Am J
Health Educ. 2006;37(6):337-343. doi:10.1080/19325037.2006. 10598924

32. Murphy J, Murphy MH, MacDonncha C, Murphy N, Nevill A, Woods C. Validity and reliability of three self-report instruments for assessing attainment of physical activity guidelines in university students. Meas Phys Educ Exerc Sci. 2017;21(3):134-141. doi:10. 1080/1091367X.2017.1297711

33. International Physical Activity Questionnaire. Guidelines for data processing and analysis of the International Physical Activity Questionnaire (IPAQ). 2005. www.ipaq.ki.se. Accessed February 1, 2017.

34. Bauman A, Bull F, Chey T, et al. The international prevalence study on physical activity: results from 20 countries. Int J Behav Nutr Phys Act. 2009;6:21. PubMed ID: 19335883 doi:10.1186/1479-5868-6-21

35. Woods CB, Tannehill D, Quinlan A, Moyna A, Walsh J. The Children's Sport Participation and Physical Activity Study (CSPPA). Research Report No 1. Dublin, Ireland: School of Health and Human Performance, Dublin City University and Irish Sports Council; 2010.

36. Knox EC, Esliger DW, Biddle SJ, Sherar LB. Lack of knowledge of physical activity guidelines: can physical activity promotion campaigns do better? BMJ Open. 2013;3(12):e003633. PubMed ID: 24319271 doi:10.1136/bmjopen-2013-003633

37. Marshall AL, Miller YD, Burton NW, Brown WJ. Measuring total and domain-specific sitting: a study of reliability and validity. Med Sci Sports Exerc. 2010;42(6):1094-1102. PubMed ID: 19997030

38. World Health Organization. Obesity: Preventing and Managing the Global Epidemic. [Report of a WHO Consultation]. Geneva, Switzerland: WHO; 2000.

39. Ware J, Sherbourne CD. The MOS 36-item short-form health survey (SF-36): conceptual framework and item selection. Med Care. 1992;30(6):473-483. PubMed ID: 1593914 doi:10.1097/ 00005650-199206000-00002

40. Sport Northern Ireland. Northern Ireland Sport and Physical Activity Survey (SAPAS) 2010. 2010. http://www.sportni.net/sportni/wpcontent/uploads/2013/03/SAPASReport.pdf. Accessed March 30, 2017.

41. Breslin G, Nevill A, Donnelly P, Murphy M. Socio-demographic and behavioural differences and associations with happiness for those who are in good and poor health. IJHD. 2013;1(2):142-154. doi:10. 1504/IJHD.2013.055641

42. Lavikainen J, Fryers T, Lehtinen V, eds. Improving Mental Health Information in Europe. Proposal of the MINDFUL Project. Helsinki, Finland: STAKES; 2006.

43. Department of Health and IPSOS MRBI. Healthy Ireland Survey 2016 Summary of Findings. Dublin, Ireland: Stationery Office; 2016.

44. Pengpid S, Peltzer S, Kassean HK, Tsala JPT, Sychareun V, MuellerRiemenschneider F. Physical inactivity and associated factors among university students in 23 low-, middle- and high-income countries. Int J Public Health. 2015;60(5):539-549. PubMed ID: 25926342 doi:10. 1007/s00038-015-0680-0

45. Buckworth J, Nigg C. Physical activity, exercise, and sedentary behavior in college students. $J$ Am Coll Health. 2004;53(1):28-34. PubMed ID: 15266727 doi:10.3200/JACH.53.1.28-34

46. Downs A, Van Hoomissen J, Lafrenz A, Julka DL. Accelerometermeasured versus self-reported physical activity in college students: implications for research and practice. $J$ Am Coll Health. 2014;62(3):204-212. PubMed ID: 24377672 doi:10.1080/ 07448481.2013.877018

47. Stamatakis E, Coombs N, Rowlands A, Shelton N, Hilldson M. Objectively-assessed and self-reported sedentary time in relation to multiple socioeconomic status indicators among adults in England: a cross-sectional study. BMJ Open. 2014;4(11):e006034. PubMed ID: 25377012 doi:10.1136/bmjopen-2014-006034 
48. Department of Health and IPSOS MRBI. Healthy Ireland Survey 2015 Summary of Findings. Dublin, Ireland: Stationery Office; 2015.

49. Brown WJ, Bauman AE, Bull FC, Burton NW. Development of Evidence-Based Physical Activity Recommendations for Adults (18-64 years). Report Prepared for the Australian Government Department of Health. Canberra, Australia: Commonwealth of Australia; 2012.

50. Deliens T, Deforche B, De Bourdeaudhuij I, Clarys P. Determinants of physical activity and sedentary behaviour in university students: a qualitative study using focus group discussions. BMC Public Health. 2015;15:201. PubMed ID: 25881120 doi:10.1186/s12889015-1553-4

51. Plotnikoff RC, Costigan SA, Williams RL, et al. Effectiveness of interventions targeting physical activity, nutrition and healthy weight for university and college students: a systematic review and metaanalysis. Int J Behav Nutr Phys Act. 2015;12:45. PubMed ID: 25890337 doi:10.1186/s12966-015-0203-7

52. Dinger MK, Brittain DR, Hutchinson SR. Associations between physical activity and health-related factors in a national sample of college students. J Am Coll Health. 2014;62(1):67-74. PubMed ID: 24313698 doi:10.1080/07448481.2013.849710

53. Morgan K, McGee H, Watson D, et al. SLÁN 2007: Survey of Lifestyle, Attitudes \& Nutrition in Ireland: Main Report. Dublin, Ireland: Department of Health and Children; 2008.
54. Trockel M, Barnes M, Egget D. Health-related variables and academic performance among first-year college students: implications for sleep and other behaviors. J Am Coll Health. 2000;49(3):125-131. PubMed ID: 11125640 doi:10.1080/07448480009596294

55. Houghton F, Keane N, Murphy N, Houghton S, Dunne C. Tertiary level students and the Mental Health Index (MHI-5) in Ireland. Irish J Appl Soc Stud. 2011;10(1):7.

56. Macaskill A. The mental health of university students in the United Kingdom. Br J Guid Counc. 2012;41(4):426-441. doi:10.1080/ 03069885.2012.743110

57. Richardson N, Clarke N, Fowler C. A Report on the All-Ireland Young Men and Suicide Project. Ireland, Europe: Men's Health Forum in Ireland; 2013.

58. Nguyen-Michel ST, Unger JB, Hamilton J, Spruijt-Metz D. Associations between physical activity and perceived stress/hassles in college students. Stress Health. 2006;22(3):179-188. doi:10.1002/smi.1094

59. Joseph RP, Royse KE, Benitez TJ, Pekmezi DW. Physical activity and quality of life among university students: exploring self-efficacy, self-esteem, and affect as potential mediators. Qual Life Res. 2014;23(2):659-667. doi:10.1007/s11136-013-0492-8

60. Piqueras JA, Kuhne W, Vera-Villarroal P, Van Straten A, Cuijpers P. Happiness and health behaviours in Chilean college students: a crosssectional survey. BMC Public Health. 2011;11:443. PubMed ID: 21649907 doi:10.1186/1471-2458-11-443 